\title{
Thermal Reactive Ion Etching of Minor Metals with $\mathrm{SF}_{6}$ Plasma
}

\author{
Gang Han, Yuki Murata, Yuto Minami, Masayuki Sohgawa, and Takashi Abe* \\ Niigata University, 8050 Ikarashi 2 Nocho, Nishi-ku, Niigata 950-2181, Japan
}

(Received August 1, 2016; accepted January 30, 2017)

Keywords: thermal reactive ion etching, minor metal, $\mathrm{SF}_{6}$ plasma, titanium

In this study, thermally assisted reactive ion etching (TRIE) was evaluated by both experiments and simulations. TRIE employs a self-heated stage instead of the etching stage of a regular RIE apparatus. The self-heated stage was designed on the base of the simulation results, and its heating characteristics upon the application of radio frequency (RF) power were evaluated. The temperature of the stage increases rapidly within 10 min because of the low thermal capacitance of the stage. An etch rate of $0.6 \mu \mathrm{m} / \mathrm{min}$ and an etch selectivity of about 30 were achieved for titanium etching with $\mathrm{SF}_{6}$ plasma. In addition, we also investigated the application of TRIE for various kinds of minor metals (Mo, Ta, Nb, and Ti alloy) for the first time and achieved higher etch rates and etch selectivities than those of regular reactive ion etching (RIE).

\section{Introduction}

As is well known, micro-electromechanical systems (MEMS) have relied heavily on materials used in integrated circuit fabrication, such as single-crystal silicon. However, owing to the special properties of metals, glasses, and piezoelectric ceramics, the use of these materials in MEMS is increasing rapidly. ${ }^{(1,2)}$

Titanium, tantalum, niobium, and molybdenum are often classified as minor metals. Some of them have special characteristics such as biocompatibility, corrosion resistance and high toughness. These characteristics make these metals applicable to various fields of MEMS, for example, medical implants and tough sensors. ${ }^{(3)}$ In addition, it makes deep reactive ion etching of these hardto-etch materials attractive.

Fluorine-containing gases, such as $\mathrm{CF}_{4}, \mathrm{C}_{4} \mathrm{~F}_{8}$, and $\mathrm{SF}_{6}$, are most commonly used in dry etch processing. However, when these gases are used to etch these minor metals, reaction products are formed on the surface. As shown in Table 1, compared with silicon tetrafluoride, these reaction products are nonvolatile, and this is why these materials are defined as hard-to-etch materials. ${ }^{(4)}$ However, for MEMS based on minor metals to become a competitive alternative to traditional silicon-based devices, we must achieve a high etch rate, high mask selectivity and high aspect ratio. The use of chlorine gas is an alternative enabling us to achieve a high etch rate. ${ }^{(5)}$ However, its application is restricted because of the safety issues associated with the use of chlorine. Another way is to use an inductive coupled plasma etching machine to etch these materials. ${ }^{(6)}$ However, it requires an inductive coupled plasma source.

"Corresponding author: e-mail: memsabe@eng.niigata-u.ac.jp http://dx.doi.org/10.18494/SAM.2017.1444 
Table 1

Boiling temperature of the reaction products at one atmosphere. ${ }^{(4)}$

\begin{tabular}{lccc}
\hline Material & Reaction products & Melting temperature $\left({ }^{\circ} \mathrm{C}\right)$ & Boiling temperature $\left({ }^{\circ} \mathrm{C}\right)$ \\
\hline \multirow{2}{*}{$\mathrm{Ti}$} & $\mathrm{TiF}_{3}$ & 950 & - (no data) \\
& $\mathrm{TiF}_{4}$ & 377 & 284 (sublime) \\
\hline \multirow{3}{*}{$\mathrm{Mo}$} & $\mathrm{MoF}_{3}$ & $>600$ & - \\
& $\mathrm{MoF}_{4}$ & decompose & 213 \\
& $\mathrm{MoF}_{5}$ & 67 & 34 \\
\hline $\mathrm{Ta}$ & $\mathrm{MoF}_{6}$ & 17.5 & 230 \\
\hline \multirow{2}{*}{$\mathrm{Nb}$} & $\mathrm{TaF}_{5}$ & 97 & - \\
& $\mathrm{NbF}_{3}$ & - & 234 \\
\hline $\mathrm{Si}$ & $\mathrm{NbF}_{4}$ & $>350$ & -86 \\
\hline
\end{tabular}

To overcome this problem of nonvolatile reaction products, we must improve the temperature of these reaction products. On the basis of this idea, our group proposed a simple method of thermal reactive ion etching (TRIE). ${ }^{77,8)}$ In TRIE, the temperature of the substrate is increased selectively and rapidly by placing a self-heated stage on the cathode of a regular reactive ion etching (RIE) system to increase the etch rate.

Figure 1 shows a schematic of the concept of the specially designed etching stage (self-heated stage). An aluminum plate is used for the stage. When the plasma is activated, the stage is exposed to ion bombardment and receives energy from the ion bombardment, radio frequency (RF) power, and thermal radiation of plasma. The low thermal capacitance of the stage ensures that these energies rapidly increase the temperature of the middle part.

In this study, we redesigned the stage to make the middle part larger than the stage described in Ref. 7 and evaluated the thermal response of the newly designed self-heated stage by both experiment and simulation. Then titanium was used in the initial etching tests. Finally, we etched various kinds of minor metals and evaluated the TRIE processing characteristics of these materials in terms of the etching depth, cross-sectional profile, and surface roughness.

\section{Materials and Methods}

\subsection{Simulation}

We used SolidWorks 2014 software (Dassault Systems) to simulate the thermal response of the self-heated stage before the experiment. The shape and size of the stage are shown in Fig. 1. The temperature of the leg part was always $293 \mathrm{~K}$ during TRIE processing, the thermal radiation coefficient of the stage was 0.4 , and the applied RF power was $100 \mathrm{~W}$. Here, we assumed $70 \%$ of the RF power was absorbed by the stage.

\subsection{Experimental process}

Figure 2 shows the experimental process. Nickel was chosen as the mask material as it reacts negligibly with fluorine-based gas. In the first step, a layer comprising chromium ( $3 \mathrm{~nm})$ and gold (30 $\mathrm{nm}$ ) was deposited on the wafer surface to increase the adhesion between the substrate and nickel 


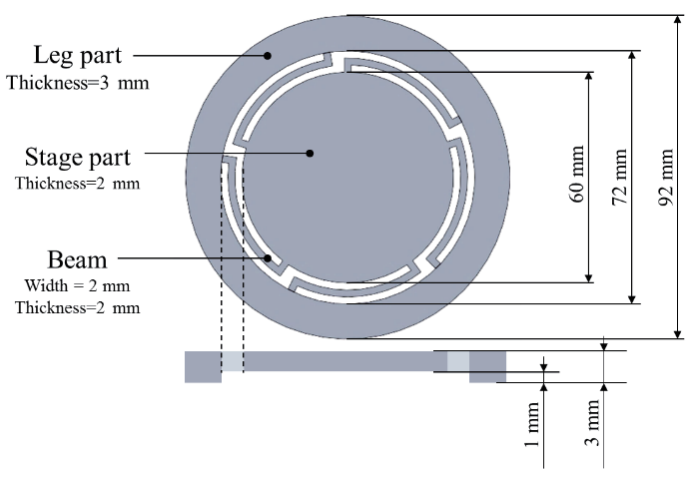

(a)

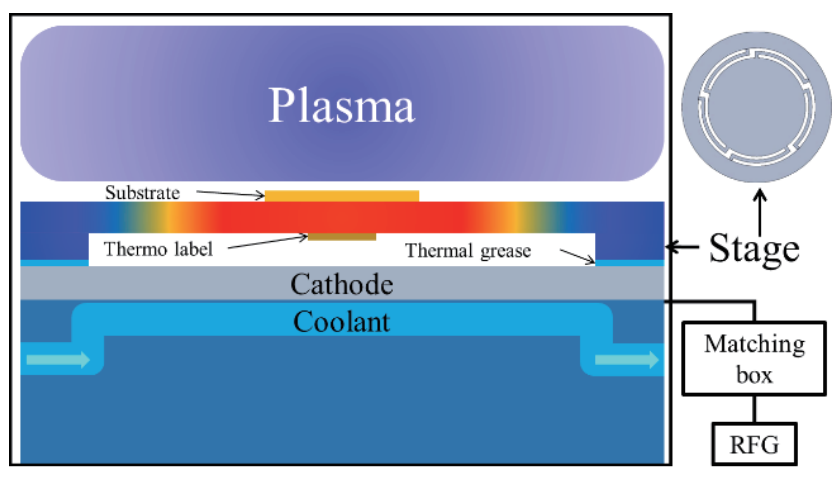

(b)

Fig. 1. (Color online) Example of the specially designed self-heated stage.

\section{Au/Cr deposition}

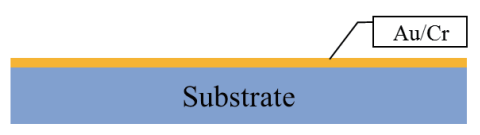

4.Electroplating of Nickel

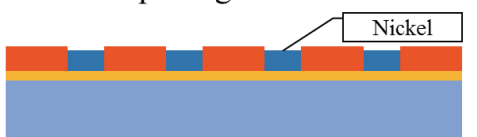

\section{Coat photoresist}

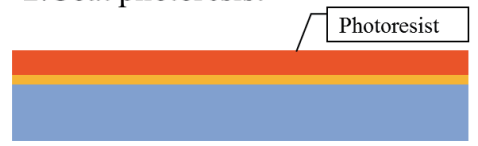

5.Remove photoresist

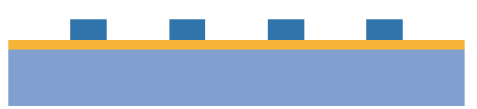

3.Photolithography

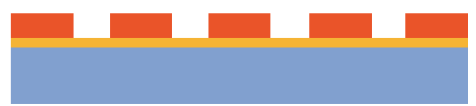

6.RIE/TRIE processing

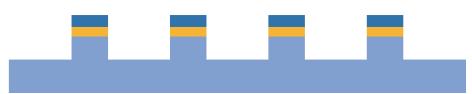

Fig. 2. (Color online) Experimental process.

mask. This mask can be removed in the first $10 \mathrm{~s}$ of the etching process. In the second and third steps, the photoresist AZP4620 was chosen to form a mask pattern because of its high contrast and high tolerance in plating. ${ }^{(9,10)}$ The mask pattern was lines with a length of $3500 \mu \mathrm{m}$ and a width of $100 \mu \mathrm{m}$, the trough width and intervals were $100 \mu \mathrm{m}$. After the photolithography, we plated a layer of nickel by electrolysis pulse plating in a sulfamic acid nickel bath. The plating time was $60 \mathrm{~min}$ and the thickness of the nickel was about $3 \mu \mathrm{m} .{ }^{(11)}$ In the fifth step, the photoresist was removed using acetone. Then the substrate was processed by regular RIE or TRIE.

\subsection{Experimental materials}

Table 2 shows the dimensions and compositions of our minor metal materials. Titanium, molybdenum, tantalum, and niobium were purchased from Nilaco Corporation. Titanium alloy was purchased from Furuuchi Chemical Corporation.

\subsection{Experimental conditions}

Figure 3(a) shows our experimental conditions. We used magnetron-type capacitively coupled plasma (CCP) RIE equipment (TEP-01, Tateyama Machine Co., Ltd.) with $\mathrm{SF}_{6}$ gas to etch the minor metals [Fig. 3(b)]. The processing time was 30 or $60 \mathrm{~min}$. Figure 4 shows the experimental setup of the regular RIE and TRIE. 
Table 2

Minor metal materials.

\begin{tabular}{lcc}
\hline Substrate material & Dimensions & Component \\
\hline $\mathrm{Ti}$ & & Ti- $99.5 \%$ \\
$\mathrm{Mo}$ & & Mo- $99.95 \%$ \\
$\mathrm{Ta}$ & & $\mathrm{Ta}-99.95 \%$ \\
$\mathrm{Nb}$ & & $\mathrm{Nb}-99.9 \%$ \\
$\mathrm{Ti}$ alloy & & $\mathrm{Ti}-90 \% \mathrm{Al}-6 \% \mathrm{~V}-4 \%$ \\
\hline
\end{tabular}

\begin{tabular}{lc}
\hline \multicolumn{2}{c}{ RIE/TRIE process conditions } \\
\hline Plasma generation method & Magnetron-type CCP \\
Cathode temperature & $293 \mathrm{~K}$ \\
Stage size & $\phi 90 \mathrm{~mm}$ \\
High-frequency power & $1.6 \mathrm{~W} / \mathrm{cm}^{2}$ \\
Reactive gas & $\mathrm{SF}_{6}$ \\
Gas flow & $15 \mathrm{sccm}$ \\
Process time & 30 or $60 \mathrm{~min}$ \\
Chamber pressure & $0.3 \mathrm{~Pa}$ \\
\hline
\end{tabular}

(a)

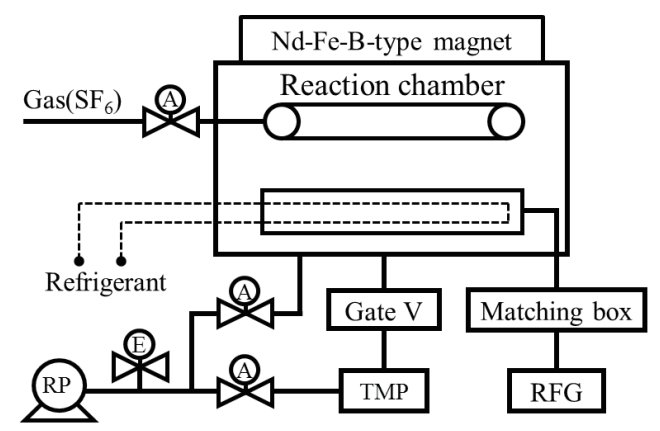

(b)

Fig. 3. Experimental conditions.
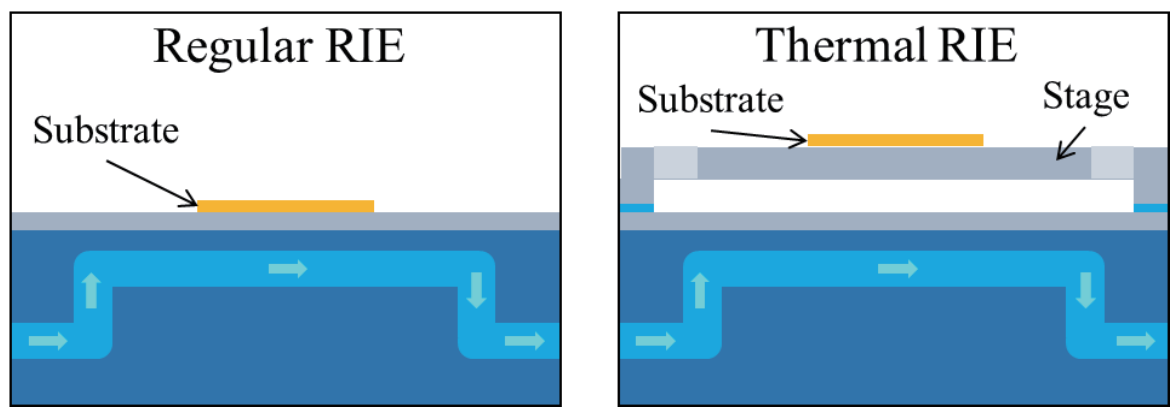

Fig. 4. (Color online) Schematic illustrations of the experimental setup.

\section{Results}

Figure 5 shows an example of the simulation result for the temperature distribution and the heating characteristics obtained from experimental results. Figure 5(a) shows that the temperature of the stage can be increased to about $521 \mathrm{~K}$ in just $10 \mathrm{~min}$. As shown in Fig. 5(b), the temperature of the middle part of the stage ranges from 525 to $529 \mathrm{~K}$. The uniformity of temperature is sufficient for processing by TRIE.

We measured the height of nickel before and after the RIE or TRIE processing, and the depth of the processed parts of minor metals after the RIE or TRIE processing to calculate the average etch rate and selectivity. Figure 6 shows the etch rate and selectivity ratio of nickel to titanium. 


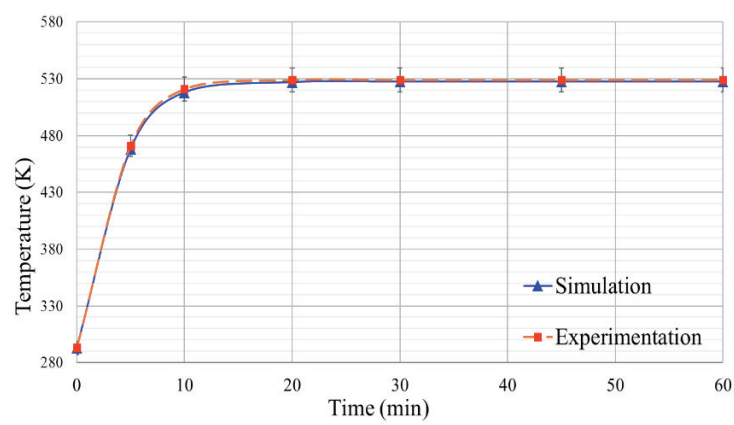

(a)

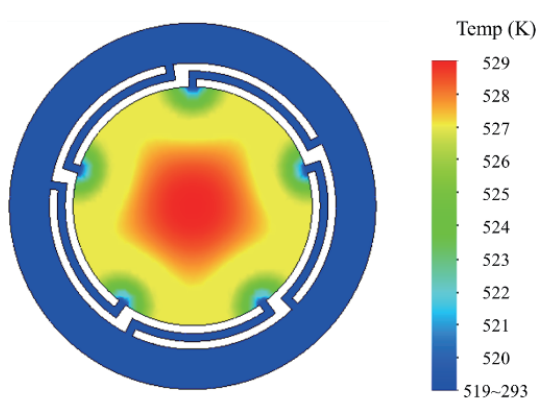

(b)

Fig. 5. (Color online) Thermal response of the specially designed self-heated stage. (a) Temperature of stage. (b) Temperature distribution of stage.

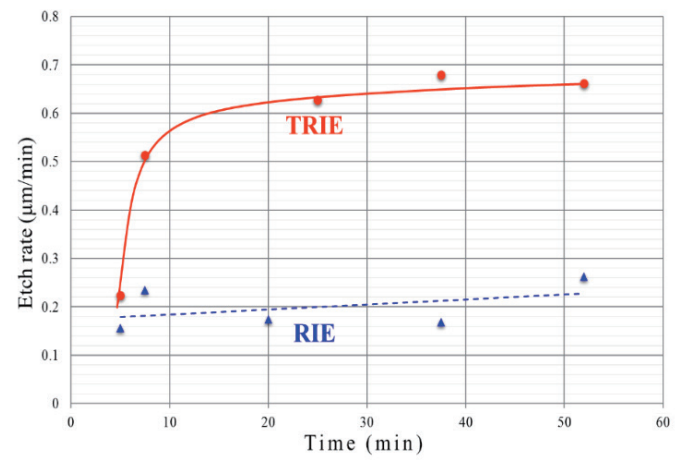

(a)

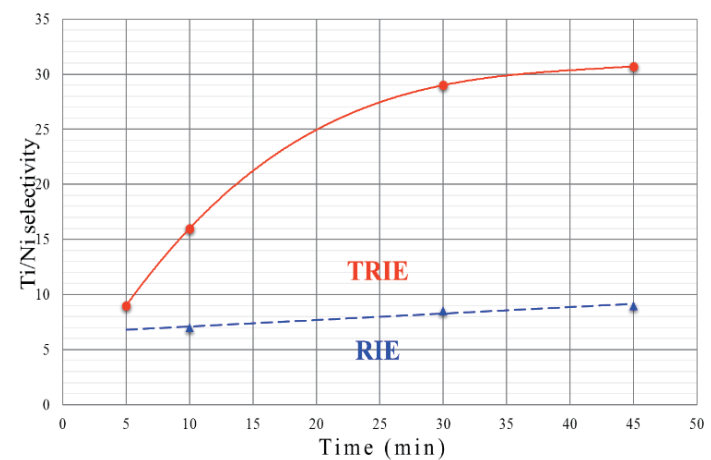

(b)

Fig. 6. (Color online) Etching characteristics for TRIE and regular RIE. (a) Etch rate of titanium. (b) Selectivity ratio of nickel to titanium.

From Fig. 6(a), we can see that the etch rate of TRIE varies with the temperature of the stage and becomes about $0.6 \mu \mathrm{m} / \mathrm{min}$ in $10 \mathrm{~min}$, which is three times higher than that achieved using regular RIE. Figure 6(b) shows that the selectivity of TRIE can reach values of about 29 in 30 min, which is much higher than that achieved for regular RIE.

Figure 7 shows the etch rates of the minor metals by TRIE and regular RIE, where the processing time was $30 \mathrm{~min}$. The etch rates of $\mathrm{Ti}, \mathrm{Mo}$, and $\mathrm{Nb}$ in TRIE are much higher than those by RIE, and the etch rates of Ta and Ti-6Al-4V are slightly higher than those by RIE. Although the effect of TRIE is different for the various minor metals, it did greatly improve the etch rate of these materials.

Figure 8 shows a cross-sectional view of these minor metals. It can be seen that problems associated with TRIE are undercutting and high surface and sidewall roughnesses.

Table 3 shows the surface roughness and sidewall angle of these minor metals. Surface roughnesses of Mo and $\mathrm{Nb}$ in TRIE are slightly higher than those in RIE. Surface roughnesses of $\mathrm{Ti}$ and Ta in TRIE are much higher than those in RIE. The surface roughness of Ti alloy in TRIE is the same as that in RIE. 


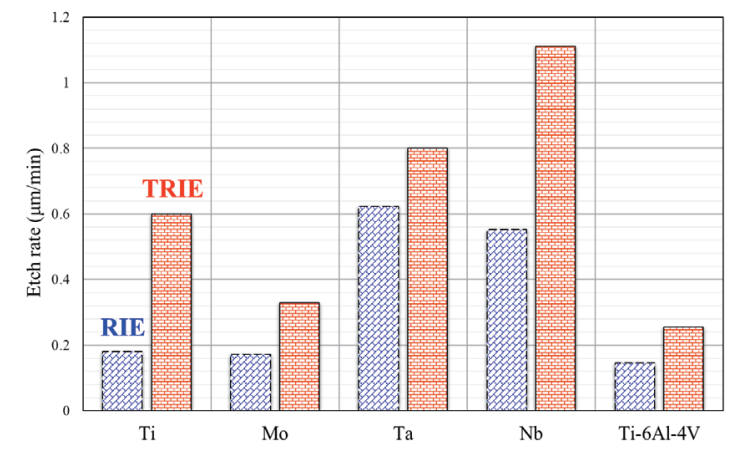

Fig. 7. (Color online) Etch rates by TRIE and regular RIE.

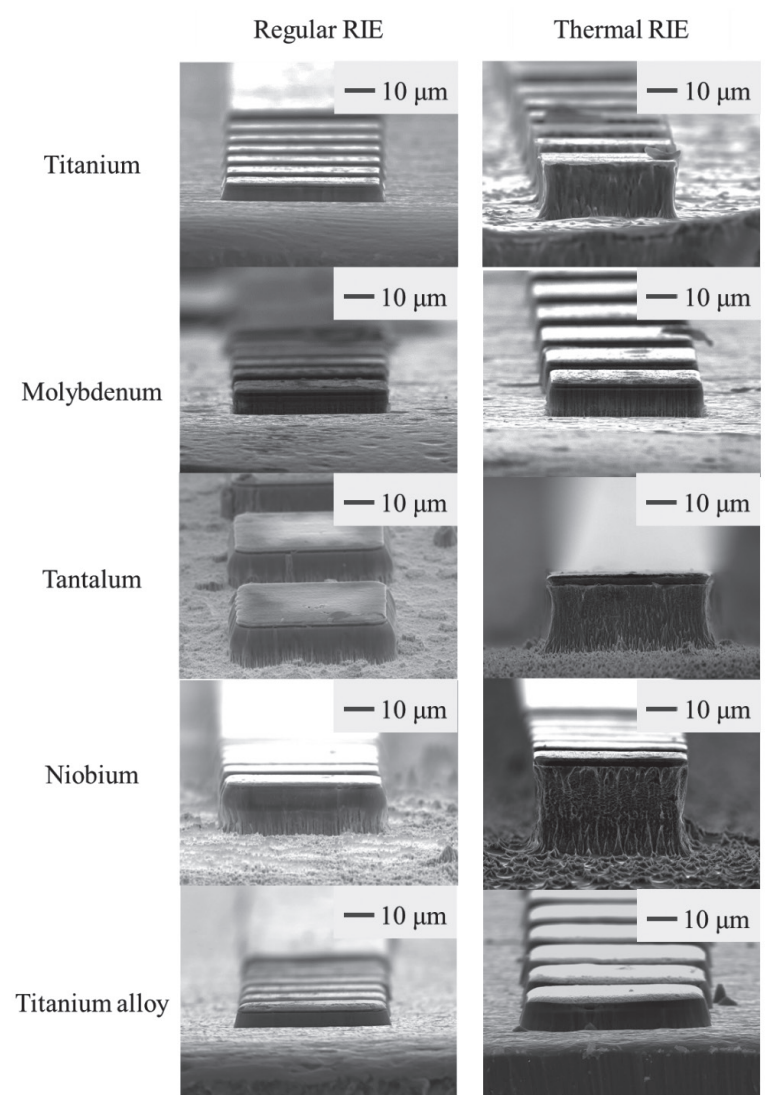

Fig. 8. Cross-sectional views of processed minor metals.

Table 3

Surface roughness and sidewall angle.

\begin{tabular}{lcccc}
\hline \multirow{2}{*}{ Material } & \multicolumn{2}{c}{ Surface roughness $(R a)$} & \multicolumn{2}{c}{ Sidewall angle $\left(^{\circ}\right)$} \\
\cline { 2 - 5 } & RIE & TRIE & RIE & TRIE \\
\hline $\mathrm{Ti}$ & $0.09 \mu \mathrm{m}$ & $0.43 \mu \mathrm{m}$ & 72 & Slight undercut \\
$\mathrm{Mo}$ & $0.06 \mu \mathrm{m}$ & $0.15 \mu \mathrm{m}$ & 90 & 90 \\
$\mathrm{Ta}$ & $0.38 \mu \mathrm{m}$ & $2.17 \mu \mathrm{m}$ & 80 & Slight undercut \\
$\mathrm{Nb}$ & $0.57 \mu \mathrm{m}$ & $0.66 \mu \mathrm{m}$ & 83 & 90 \\
$\mathrm{Ti}$ alloy & $0.10 \mu \mathrm{m}$ & $0.10 \mu \mathrm{m}$ & 70 & 76 \\
\hline
\end{tabular}

\section{Discussion}

The undercut produced by the TRIE process can be reduced by adjusting the temperature and the RF power, and the etched surface and sidewall roughnesses can be reduced by the addition of argon gas and/or $\mathrm{C}_{4} \mathrm{~F}_{8}$ gas. A slight addition of atoms ( $\mathrm{Al} 6 \%, \mathrm{~V} 4 \%$ ) makes titanium alloy hard to etch because of the high boiling temperature of $\mathrm{AlF}_{3} \cdot{ }^{(4)}$ However, not all the differences in the etch rates of these minor metals can be explained simply by the differences in the boiling temperature of reaction products. In the case of molybdenum, the chemical species of etch products and the binding energy must also be considered. 


\section{Conclusions}

The thermal response of a newly designed self-heated stage was evaluated and the results showed that its use can make a regular RIE system more effective even without the use of an inductively coupled plasma source. The TRIE etching characteristics of titanium, titanium alloy, molybdenum, tantalum, and niobium were evaluated, and the results showed that this method can greatly improve the etch rate and mask selectivity of these minor metals. However, TRIE still has some problems with regard to the etching surface and sidewall shape of minor metals, and thus, further optimization, such as the improvement of surface roughness, is necessary.

\section{Acknowledgements}

This work was supported in part by a Grant-in-Aid for Scientific Research from the Ministry of Education, Science, Sports and Culture of Japan (16H03840) and by a Grant-in-Aid from Japan Science and Technology Agency.

\section{References}

1 M. F. Aimi, M. P. Rao, N. C. Macdonald, A. S. Zuruzi, and D. P. Bothman: Nat. Mater. 3 (2004) 103.

2 X. H. Li, T. Abe, and M. Esashi: Sens. Actuators, A 87 (2001) 139.

3 E. R. Parker, M. P. Rao, K. L. Turner, C. D. Meinhart, and N. C. MacDonald: J. Microelectromech. Syst. 16 (2007) 289.

4 W. M. Haynes: Handbook of Chemistry and Physics, 95th ed. (CRC, 2014).

5 F. Fracassi and R d'Agostino: Pure Appl. Chem. 64 (1992) 703.

6 E. R. Parker, B. J. Thibeault, M. F. Aimi, M. P. Rao, and N. C. MacDonald: J. Electrochem. Soc. 152 (2005) 675.

7 S. Yamada, Y. Minami, M. Sohgawa, and T. Abe: Rev. Sci. Instrum. 86 (2015) 045001.

8 S. Yamada, H. Takeshi, M. Sohgawa, and T. Abe: IEEJ Trans. Sensors and Micromachines 134 (2014) 96 (in Japanese).

9 M. L. Wang, J. M. Zheng, and D. H. Sun: MEMS Device Technol. 41 (2004) 27.

10 B. L. Luo, J. L. Du, X. G. Tang, C. L. Du, S. J. Liu, and Y. K. Guo: Semicond. Technol. 30 (2005) 34 (in Chinese).

11 H. Kunisuke and T. Yutaka: J. Surf. Finishing Soc. Jpn. 30 (1983) 524 (in Japanese). 